- that is, the presence of a ninhydrin reactor (Fig. 1, symba 18) not reported by Dent (1948) as occurring in human urine. Work on the isolation and identification of this compound will form the basis of a separate communication. In conclusion it can be said that resection of $16 \%$ of the liver produced no specific change in amino-acid metabolism.

\section{Urinary Urobilin(ogen)}

Before resection the excretion was within normal limits. During the eight days immediately following operation the excretion was excessive on five days, the peak being reached on the sixth day. This was in fact a quantitative change in the excretion of urobilin(ogen), as allowance was made for variations in the 24-hour urine volumes. Control observations were made on eight cases following surgery of comparable severity. The results are shown in Table II. Reference to this

TABLE II

\begin{tabular}{|c|c|c|c|c|c|c|c|c|c|}
\hline \multirow{2}{*}{ Operation } & \multirow{2}{*}{ 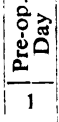 } & \multicolumn{8}{|c|}{ Post-op. Days } \\
\hline & & 1 & 2 & 3 & 4 & 5 & 6 & 7 & 8 \\
\hline Part. hepatectomy & - & - & + & + & 0 & ++ & +++ & ++ & - \\
\hline $\begin{array}{l}\text { Part. gastre tomy } \\
\text { Lobectomy } \\
\text { Thoracoplasty... } \\
\text { Laminectomy .. } \\
\text { Oesophagectomy } \\
\text { Cholecystectomy } \\
\text { (without biliary } \\
\text { drainage) } \\
\text { Blood transfusion } \\
\text { (3 pints) }\end{array}$ & $\begin{array}{l}= \\
= \\
= \\
= \\
- \\
-\end{array}$ & $\begin{array}{l}0 \\
\overline{0} \\
0 \\
0 \\
- \\
+ \\
-\end{array}$ & $\begin{array}{l}\overline{-} \\
\overline{0} \\
\overline{-} \\
- \\
-\end{array}$ & $\begin{array}{l}- \\
\overline{-} \\
\overline{-} \\
\overline{-}\end{array}$ & $\begin{array}{l}\bar{z} \\
\overline{+} \\
\overline{+} \\
+ \\
- \\
-\end{array}$ & $\begin{array}{c}\overline{-} \\
\overline{+} \\
\overline{+}+\end{array}$ & $\begin{array}{c}\overline{-} \\
\overline{-} \\
++ \\
\overline{+}+\end{array}$ & $\begin{array}{l}- \\
\overline{0} \\
0 \\
\overline{0}\end{array}$ & \\
\hline
\end{tabular}
moderate excess; $+\overrightarrow{+}+$, marked excess.

table shows that, while several of the controls did have excess urobilin(ogen) excretion post-operatively, in none was it manifest so early or so markedly as in the patient subject to partial hepatectomy. It seems possible, therefore, that part of this increase is directly attributable to decrease of liver mass available for disposal of the chromagen arriving via the portal vein.

Further control observations on a patient who received a transfusion of 3 pints (1.7 litres) of blood established that this alone was not likely to be responsible for the increased urobilin(ogen) in the urine following the resection.

\section{Summary and Conclusions}

Liver-function tests were performed before and after resection of $16 \%$. of the liver in a case of primary liver-cell carcinoma occurring in a non-cirrhotic organ.

The serum flocculation tests and the urinary excretion of urobilin(ogen) alone showed changes believed to be attributable to partial resection of the liver.

The serum proteins and the pattern of amino-acids in the blood and urine showed changes which are believed to be non-specific in relation to the operation.

The following tests failed to register the surgical intervention: plasma prothrombin concentration, blood urea, serum bilirubin, hippuric acid synthesis, bromsulphthalein clearance, serum alkaline phosphatase.

We wish to thank Mr. H. R. I. Wolfe, the surgeon in charge, for permission to publish this report, and Mr. A. G. Riddell, through whose co-operation we were able to carry out this investigation.

\section{REFERENCES}

Abercrombie, M., and Harkness, R. D. (1951). J. Physiol., 113, $7 P$.

Berman, C. (1951). Primary Carcinoma of the Liver. Lewis, London. Boyd, W. (1944). Pathology of Internal Diseases. Kimpton,
London.

Counseller, V. S., and McIndoe, A. H. (1926). Arch. intern. Med., 37, 363.

Dent, C. E. (1947). Biochem. J., 41, 240

(1948). Ibid., 43, 169.

- (1949). Biochem. Soc. Symposia, No. 3, p. 34.

and Walshe, J. M. (1951). Ciba Foundation Conference on Liver Injury. Churchill, London. In press.

Ferrari, V., and Harkness, R. D. (195i). J. Physiol., 113, 27P.

Hoyne, R., M., and Kernohan, J. W. (1947). Arch. intern. Med. 79, 532 .

Maclagan, N. F., and Bunn, D. (1947). Biochem. J., 41, 580

Mallory, T. (1948). New Engl. J. Med., 238, 26.

Neefe, J. R., Gambescia, J. M., Gardner, H. T., and Knowlton, M. (1950). Amer. J. Med., 8, 600

Popper, H., Steigmann, F., Meyer, K: A., Kozoll, D. D., and Franklin, M. (1949). Ibid., 6, 278.

Scurry, M. M., and Field, H. (1943). Amer. J. med. Sci., 206, 243.

Tull, J. C. (1932). J. Path. Bact., 35, 557.

Turner, G. Grey (1923). Proc. roy. Soc. Med., 16 (Sect. Surg.), 43.

Warner, E. D. (1938). J. exp. Med., 68, 831

Willis, R. A. (1948). Pathology of Tumours. Butterworth, London.

\section{BONE DYSTROPHY IN ASSOCIATION WITH MUSCULAR DYSTROPHY (MYOPATHY)}

\author{
BY \\ D. W, ASHBY, M.D., M.R.C.P. \\ G. E. O. WILLIAMS, M.D., M.R.C.P. \\ O. E. SMITH, M.B., Ch.B., D.M.R.D.
}

In 1905 Professor Spiller stated that implication of the bones in progressive muscular dystrophy was not often observed, and that many of the textbooks on nervous diseases made no mention of it. This statement is almost as true now as it was then, and, although bone changes in poliomyelitis, syringomyelia, and other neuromuscular disorders are frequently described in standard textbooks, their association with primary muscular dystrophy is rarely mentioned.

Marie and Crouzon (1903) reported a case of muscular dystrophy with fracture and atrophy of the humerus. Spiller (1905), in an account of a case of muscular dystrophy with wasting of the humerus scapula, and acromion process, gave as his earliest reference that of Lloyd (1884); however, Friedreich had discussed the subject at length in 1873 and had referred to an earlier observation of Le Gendre.

Bone changes mentioned in the literature include not only kyphoscoliosis and deformities of the skull, foot, and pelvis, but also atrophy of the clavicles, scapulae, ribs, and innominate bones, and atrophy, narrowing, and, less frequently, shortening of the long bones. The latter have often a shaft of reduced width, the reduction of the medullary canal being more marked than that of the cortex, whereas the epiphyses may be of normal diameter, giving an attenuated dumbbell shape to the affected long bones. Zellweger (1946) described five patients whose pelves were $x$-rayed, and who were said to have coxa valga; one was shown to have bilateral dislocation of the hips with hypoplasia of the acetabula. 


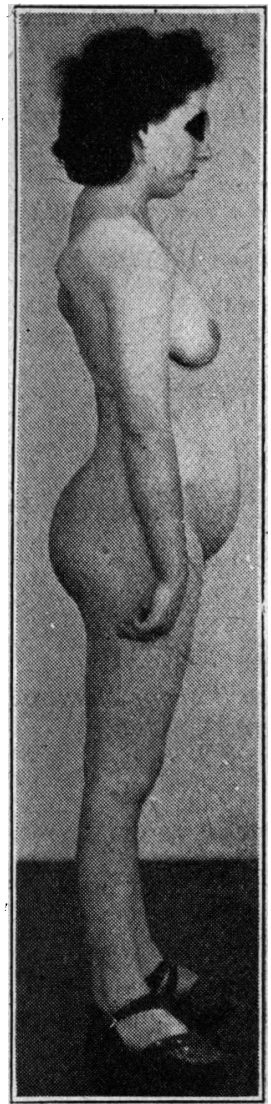

Fig. 1.-Profile of patient, s h o w i n g typical stance with lordosis, feet astride, lordosis, feet astride,
and scapulae winged.
The patella in one case, by loss of its bony structure, resembled a thinwalled cyst described by Merle and Raulot-Lapointe (1909) as " rotule de verre."

In discussing causes most authors discount muscular inactivity. Curschman (1936) often found no bone atrophy in advanced muscular dystrophý. Maybarduk and Levine (1941) pointed out that bones were affected which could hardly have been influenced by muscular disuse -for example, shortening of the vertical ramus of the lower jaw was noted, though masticatory muscles were not involved in the dystrophy. They referred to Eu'enburg's (1896) case of muscular dystrophy, in which both atrophy and hypertrophy of the bones were found.

In describing the following case we again draw attention to the occurrence of bone changes in primary muscular dystrophy.

\section{Case Report}

A woman aged 28 was admitted to hospital on July 19, 1949. At the age of 12 she fell from a gate, fracturing her right clavicle. One year later she noticed a weakness of her arms, which she at first attributed to her fall. The weakness affected the muscles of the upper arms and shoulders, so that she could not get her hands up to do her hair and had to support her elbows on the dressing-table. She received massage treatment without improvement, but the condition did not seem to get any worse until the birth of a stillborn child in 1942 after a pregnancy complicated by high blood presşure. After the puerperium the left leg appeared to be weak and heavy, and her muscles ached after exertion. The condition of the arms did not seem to have deteriorated.

Examination showed the patient to be a well-nourished young woman, weight $8 \mathrm{st} .13 \mathrm{lb}$. (56.7 kg.), height $5 \mathrm{ft} .2$ in. $(157.5 \mathrm{~cm}$.). There was marked lordosis (Fig. 1) with compensatory upper dorsal kyphosis, and bilateral talipes equinovarus. Both shoulder-blades appeared to be small, the left measuring 6 in. $(15 \mathrm{~cm}$.) along its vertebral border, the

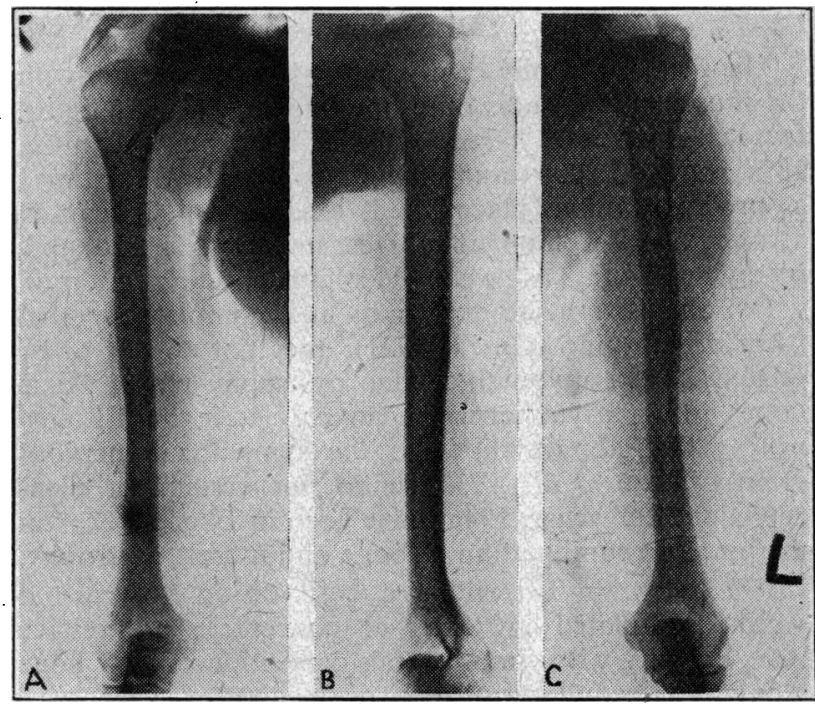

Frg. 3.-A. Patient's right humerus. B. Left humerus of a normal control of same age and height. C. Patient's left humerus. Note the attenuated dumbbell appearance given to the patient's right humerus by the comparatively slender shaft. The medullary diameter is much reduced though the cortex is of average depth.

right $5 \frac{1}{2}$ in. $(13.8 \mathrm{~cm}$.). They were highly placed, giving a Sprengel's type of shoulder deformity, and were also winged. The gait was of "myopathic" type, and it had been originally suggested that she might have a congenital dislocation of the hip. On attempting to rise from the floor, she went through the evolutions known as "Gowers's pathognomonic figures."

There was weakness of the shoulder girdle muscles, particularly deltoids, pectoralis major, trapezius, rhomboids, and serratus magnus. The left trapezius and both deltoids were wasted, though facial musculature and sternomastoids appeared normal. The muscles of the arms and forearms were also involved, particularly the trieeps and brachioradialis on the right side, with 1 in. $(2.5 \mathrm{~cm}$.) of wasting of the right arm. There was no loss in the power of grip. The arm reflexes were uniformly diminished, with the exception of the left supinator jerk. Weakness also involved the legs, so that flexion of the hip and knee, dorsiflexion, plantar flexion, and eversion of the feet were difficult. "These changes were more marked in the left leg and thigh, and the left thigh showed $\frac{3}{4}$ in. $(1.9 \mathrm{~cm}$.) wasting. The abdominal muscles were all extremely weak, and so were the sacrospinalis group, particularly on the left side. There was no pseudo-hypertrophy of the affected muscles and they did not fibrillate. There were no sensory, pyramidal tract, or cerebellar abnormalities.

Radiographs of the arms and shoulder girdles showed the right scapula to be elevated and hypoplastic (Fig. 2). The left scapula, though by no means, as underdeveloped as the right, was also on the small side. The right humerus was shorter than the left, and was also shorter than a wellselected control (Fig. 3). The right humeral shaft was narrow, the medullary diameter being much reduced, while the cortex was of average depth. The extremities of the humerus were nearly normal in size, and the cancellous texture was not altered. No overall reduction in calcium content was , indicated by the $x$-ray films. Radiographs of the rest of the skeleton revealed no abnormality, there being no hip dislocation.

The patient's three sisters and one brother, and a.nephew aged $2 \frac{1}{2}$, were examined clinically and radiologically, but showed no evidence of either myopathy or bone dystrophy:
FIg. 2-Showing the elevated hypoplastic right scapula of the patient (A) compared with that of a normal control (B). In taking these pictures care has been made to avoid foreshortening of the'scapula by obliquity. 


\section{Discussion}

The bone dystrophy of myopathy has in common with the muscular weakness only one undisputed aetiological factor, which is a heredo-familial incidence (Schultze, 1899 ; Dreyer, 1906 ; and others). Spiller (1898) assumed a process taking place in. myopathy which caused atrophy and developmental arrest in early life, probably involving bones as well. Hemiatrophy, a condition which one attempts to explain by an incomplete minimal form of twinning (Gesell, 1921), does not appear to be related, as the myopathic bone dystrophy may involve bones in an asymmetrical manner. It is hardly surprising that abnormalities of the sympathetic nervous system (Kuré et al., 1936), endocrine system, or diencephalon (Zellweger, 1946) have been invoked to explain the puzzling combination of bone and muscle dystrophy.

Friedreich, in describing a case of an 18-year-old youth, postulated an external concentric progressive bone atrophy with simultaneous deposition of new bone along the medullary surface of the cortex. He considered the process to be a nutritional atrophy rather than an arrest in development.

Despite the numerous points of similarity between this humerus and one whose development has been arrested or slowed down by paralysis-for example, acute anterior poliomyelitis-it is not easy to explain all characteristics by disuse in the absence of any osteoporosis in this case. Even the versatility of Pommer's (1925) theories of tissue pressure as a basis for the mechanism of changes in blood supply causing relative preponderance of osteoclastic or osteoblastic activity does not provide a ready explanation of why the bone should be abnormally slender and of normal density in this case. If these bones have ever been of normal dimensions the present appearances must be due to the process postulated by Friedreich. Even if the bones have developed in this fashion (never having been normal) the compactum must partially, at least, have been laid down from within in order to explain the alterations in cortex/ medullary ratio. Nevertheless, the final result in this condition, as in poliomyelitis, is in striking contrast to the thick sturdy bone with prominent muscle attachment produced by continued heavy muscular stresses. It would be impossible to assess whether developmental arrest had occurred from the time that muscular weakness became evident in this case ; the question could be answered only by repeated observation of progressive cases beginning at an early stage.

Trophic changes are not operative in the same sense as they are in tabes when kinaesthetic sensation is commonly involved and Charcot's joints occur, although the word " trophic," meaning a nutritional change, would be applicable.

Apart from recognizing familial incidence in both muscle and bone changes, we feel that there is little to be gained by theorizing upon the pathogenesis of the bone changes.

\section{Summary}

A case of myopathy showing atrophy and hypoplasia of humerus and scapula is described. Previous literature is reviewed and possible mechanisms are briefly discussed.

\section{REFERENCES}

Curschman, H. (1936). In Bumke and Foerster's Handbuch der Neurologie 16,431 .

Dreyer, L. (1906). Dtsch. Z. Nervenheilk., 31, 147.

Eulenburg, A. (1896). Dtsch. med. Wschr., 22, 458.
Friedreich, N. (1873). Ueber progressive Muskelatrophie, über wahre und falsche Muskelhypertrophie, p. 344. Hirschwald, Berlin.

Gesell, A. (1921). Arch. Neurol. Psychiat., Chicago, 6, 400.

Kuré, K., Okinaka, S., and Oshima, K. (1936). $A Z$. ges. Neurol. Psychiat., 155, 157.

Lloyd, T. H.' (1884). J. nerv ment. Dis., 9, 627

Marie, P., and Crouzon, V. (1903). Rev. neurol., 11, 239

Maybarduk, P. K., and Levine, M. (1941). Amer. J. Dis. Child. 61,565 .

Merle, P., and Raulot-Lapointe (1909). Rev. neurol., 17, 385.

Pommer, G. (1925). Arch. klin. Chir., 136, 1.

Schultze, F. (1899). Dtsch. Z. Nervenheilk., 14, 459.

Spiller, W. G. (1898). Med. Rec., N.Y., 54, 9

(1905). Rev. Neurol. Psychiat., 3, 388.

Zellweger, H. (1946). Ann. Paediat., Basel, 167, 287.

\section{A CASE OF PRIMARY AMENORRHOEA ASSOCIATED WITH ASTHMA}

BY

MAYER FROHLICH, M.R.C.S., L.R.C.P.

Honorary Clinical Assistant, West End Hospital for Nervous Diseases; Clinical Assistant, Central London

Ear, Nose, and Throat 'Hospital

\section{The Physiology of Primary Amenorrhoea}

The mechanism responsible for menstruation may be interrupted at three levels : first, the output of pituitary gonadotrophins may not suffice to stimulate the ovary to secrete oestradiol, to ovulate, and to secrete progesterone; secondly, the ovaries may be unable to respond to a normal pituitary gonadotrophic stimulus; and, thirdly, the uterus may not respond to the ovarian hormones. Primary amenorrhoea may arise at any of these levels. Pituitary deficiency may be of all degrees from the extreme of pituitary dwarfism, through decreasing grades of gonadotrophic hypoplasia, to a mere delay in the establishment of puberty and menstruation. Ovarian deficiency similarly ranges from complete agenesis to the mildest hypoplasias. An infantile uterus is only rarely seen when ovarian secretion is normal, but undue delay in the establishment of menstruation may leave the uterus irreversibly infantile.

There is little hope of curing primary amenorrhoea if an infantile body-build indicates severe pituitary hypoplasia, or if extreme ovarian deficiency is shown by a eunuchoid body-build (hormonal castrate). Success is most likely in the obese type of young woman who may perhaps be regarded as having no more than a very undue delay of puberty.

Primary amenorrhoea may be treated by either ovarian or pituitary hormones. At the lowest level intermittent oestrogen therapy will very often induce cyclical withdrawal haemorrhage from the uterus. Such bleeding may give psychological benefit, but is too far removed from the normal mechanism of menstruation to induce a normal pituitary-ovarian rhythm. Better results follow when progesterone succeeds the oestrogen-for examp'e, oestrogen for five days, progesterone for five days, and 20 days' rest. Bickers (1948) indused cyclical bleeding by this means in $60 \%$ of cases of primary amenorrhoea, and in $40 \%$ menstruation continued for at least three months after stopping treatment.

The most logical treatment of primary amenorrhoea, however, is to stimulate or reinforce the normal pituitary secretion of follicle-stimulating and luteinizing hormones. Suitable cases often respond to massive 